Covered in: Web of Sciences (WOS); EBSCO; ERIH+; Google Scholar; Index Copernicus; Ideas RePeC; Econpapers; Socionet; CEEOL; Ulrich ProQuest; Cabell, Journalseek; Scipio; Philpapers; SHERPA/RoMEO repositories; KVK; WorldCat; CrossRef; CrossCheck

\section{The Future of Social Dialogue in the Age of Artificial Intelligence}

\section{Viorel ROTILĂ ${ }^{1}$}

${ }^{1}$ PhD Univ. Prof. "Dunarea de Jos" University of Galati, Romania; Director of the „Solidaritatea” Research and Development Center, Galati, Romania. E-mail address: viorelrotila@yahoo.com,phone 0040721246491
Abstract: The survival of social dialogue depends on the extent of the social changes, being conditioned by the maintenance of the labour relations and by the models of representation of trade union type. Uncertainties regarding the future of work are automatically transformed into uncertainties regarding the future of trade unionism and social dialogue. Work is a type of social relationship that has significantly contributed to who we are. We can assume that as long as humanity lasts, work will exist (not necessarily with its present significance). We consider that the fate of social dialogue is linked to the future of trade unionism. Unions try to defend a model of balance needed within a specific type of social relations called labour relations. In order for the unions to have chances of survival (and, together with them, the social dialogue as well) these must embrace change, orientating it in the directions appropriate to their purpose. We use the phrase cyber-unionism because the main recommended way is the involvement of the unions in the use and development of AI, respectively of the new technologies and of the specific research. The overall solution: a reform of trade unionism based on a new ideology and the increase of power as a result of the use of new technologies. The scenarios proposed in this article go beyond an obvious limit: they explore the possibilities of evolution of the society using possible solutions in order to meet our current goals. The solutions discussed do not take into account the change of the wishes of the people in time, being impossible to anticipate the directions of evolution of the objectives of humanity. Our approach is between what we think it will be and what we think it should be.

Keywords: social dialogue; the future of work; cybernetic unionism; online protests; labour relations.

How to cite: Rotilă, V. (2019). The Future of Social Dialogue in the Age of Artificial Intelligence. Postmodern Openings, 10(3), 151-189. doi:10.18662/po/87 


\section{Introduction}

Asking ourselves about the future of social dialogue relations means considering the future of work. Meditating on the future of work means actually meditating on the future of social relations. This means asking us fundamental questions about the future of humanity.

We do not know any model of society in which work is absent. Even if we think of different types of societies in which the separation between social layers is profound in the work plan, we cannot exclude the fact that the ruling class has some attributions related to the field of management, that is to say, a form of work (according to its current understanding). In other words, no matter how much we are situated in a Marxist perspective when we look at the past, forcing the identification of the two social classes, we have to accept that even the forms of social domination have something like work in them (as we will see in this article, even trade unionism might be interested in such an assimilation). Work is situated within the flow of relations between self and others, being a certain type of social relationship. For the existence of work, the idea of a balance between the effort made in the interest of others and the reward received from others remains essential. At the limit, the disappearance of work could mean the disappearance of humanity in the sense that we now understand. As we are now caught up in the flow of these forms of cooperation, it is hard for us to believe that we should expect the impoverishment of social relations determined by work. However, our belief is based on the current understanding of the society, risking to miss the faces that it may take in the future.

The analysis of the future of social dialogue is carried out taking into account the information provided by the past, the values of the present and the context of the generic influences which we assume that new technologies could exert on social institutions. We are interested in the resilience of the institution of social dialogue in the context of the changes that could be brought about by the new technologies and the new axiological options of the society.

From the perspective of the present, the social dialogue presupposes trade unionism or at least alternatives such as the employees' representatives. Trade unionism is possible only under the conditions of labour/work existence. The eventual disappearance of work will automatically cause the disappearance of the main dimension of the social dialogue, having as actors the representatives of those who work and employers. Even if we consider the tendency to widen the social dialogue, introducing within it both the civil society and the state, which would generate the possibility of social dialogue 
to survive in this form for a period of time, the existence of work seems to be the sine qua non condition of social dialogue.

What do unions really try to create and defend? A model of social balance in a specific type of social relations called labour/work relations. The need for balance will exist as long as this type of social relationship lasts. But even this need for balance can vary between significant limits. Due to the speed with which social change intervenes, we are likely to witness an increase in the distance between the modes of organization envisaged by the nostalgia of union leaders and the reality of social relations during work.

\section{Methodological aspects}

An essential variable for the subject addressed is the time horizon to which we refer, in this case applying the rule of the inverse proportional relation between the distance in time and the probability of predictions. In this sense, some of our predictions and recommendations may prove relevant for the next period/first phase of the changes, significantly missing the following periods.

A Bayesian model approach is most appropriate in this area as well, updating the knowledge about new environments by generating the cognitive context for predictions with relevant probability degree.

If the social dialogue will not survive in the next phase of the evolution of the society, it is useless to talk about it in the later phases, the probability of survival/recovery becoming very low. Social dialogue is a social institution that can survive under conditions of continuity. The exception could be the definition of new relations by calling on the previous social models, as we suggest that it could happen in the case of the "dialogue" between humanity and super-intelligence.

\subsection{About the limits of knowing the future}

Self-fulfilling prophecy and self-defeating prophecy. To the extent that they enjoy the success of getting into the public's attention, predictions face two types of effects that can affect their adequacy to reality: those characteristic to self-fulfilling prophecy (in this case predictions rather play the role of ideologies) and specific ones of self-defeating prophecy. An example for the latter effects is offered by Harari, who suggests that in the social environment knowledge can in some cases reduce the predictive capacity by changing people's behaviours (Harari, 2016: 56). Harari illustrates the situation through the case of K. Marx: he was right, but the capitalists used his theories to change the situation of the workers. For our topic, we 
note that the optimistic variant of our predictive capabilities must be viewed in moderation, for two reasons: a) even if we could predict the following changes in the labour market we will not be able to anticipate the behavioural changes (which break the causal chain used within the predictions) who will be brought by these changes; b) there is a risk that an inadequate prediction will become a meme, causing social changes that would not have taken place in its absence.

This predictive weakness is specific to all social sciences, extending throughout the estimation path. Surely, the technological evolution will have an impact on the labour market, which might seem predictable to us now. However, we cannot predict the behavioural/ structural changes that both predictions in the field and technology prepare. We tend to position ourselves in the area of human work defence, for example missing the possibility of a radical paradigm shift in terms of the value of work, such as "Work is for robots!"

Between the future of the past and the past of the future. The great weakness of predictions is that they consider the present and the past rather than the future. Nor could it be otherwise, because describing the future through what is characteristic to it might be unintelligible to the people of the present. Harari calls this anticipation based on the past and present the future of the past, opposing to it the true future (Harari, 2016: 64). We can continue his idea by talking about the past of the future: we cannot predict the number of rewrites/reinterpretations of the history to be made from the perspective of a future present. The past of the future is an essential tool for all ideologies, providing a good deal of political and social legitimacy, including the one on which social dialogue is based.

\subsubsection{We cannot know what we will want in the future}

The fact that we cannot know what we will want in the future is one of the limitations of this article, inevitably operating with the thesis of stability and continuity in wanting (at least some of us) social dialogue as a value of democracy. The assumption of the continuity of desires/values is a weak one, not supported by evidence. History tends to rather highlight the desire for change, as the only exception seems to be the structures similar to the Decalogue. One possible output solution is the coherent extrapolated volition proposed by Yudkowsky: "In poetic terms, our coherent extrapolated volition is our wish if we knew more, thought faster, were more the people we wished we were, had grown up farther together; where the extrapolation converges rather than diverges, where our wishes cohere rather than interfere; extrapolated as we wish that extrapolated, interpreted as we wish 
that interpreted." (Yudkowsky, 2004: 6). However, this solution seems to involve either the difficulty of anticipating one's own wishes or the delay of the decision.

\subsubsection{Is the issue of the future ontological or moral?}

If the problem of the future is ontological then we have to keep our estimations as close to what we think it will be, the only scientific approach being the one based on the analysis of possible scenarios. However, if it relates to the moral sphere, then we must ask ourselves how we would like it to $b e$, our approach being in this case an axiological one. However, talking about the future in terms of values to be maintained/imposed places us in full ideological approach.

We believe that the combination of the two perspectives is the most appropriate solution. The presentation of some scenarios brings with it the highlight of the problems that may arise. Because our mind is shaped by the values of the present, the problems that our scenarios indicate have the character of problems only by reference to our present values. Which means that we tend to see the future as shaped by the axiological frameworks specific to the present. In other words, in each of the variants we tend to slip at the same point: we think the future predominantly from the perspective of what we consider important at present. In other words, the variant of the ontological approach has many points of connection with the axiological one. So, we are caught between what we think it will be and what we think it should be, this attitude being visible throughout the article.

\subsection{A few variables}

The change of social values. We cannot exclude the possibility that social values will undergo a significant change, either in the direction of eliminating social dialogue within them or in that of strengthening it as a social value. In the second variant, the evolution of social relations exceeds the political decision (insofar as the social values are not and will not be dependent on the political decision).

Lack of importance of citizens. If the thesis of the lack of importance of the citizens in the context of the new technologies, proposed by Harari as one of the alternatives (Harari, 2018: 21-24), is confirmed, then the predictions regarding the disappearance of the social dialogue are also correct. Such an evolution could also determine the emergence of a solution for transforming the social dialogue into the state-employer dialogue (the state or the employers in this case taking over the social roles of the unions). 


\section{Threats to trade unionism and (consequently) social dialogue}

If we agree that social dialogue implies the need for trade unions then we need to observe that recent history does not provide arguments for optimistic predictions for their future. What explains the decline of trade unionism in relation to the role it has played in the last four decades? Keune considers that we must consider a whole range of causes, including "failed union strategies, changes in the institutional environment in which unions operate, free-rider problems, and anti-union politics" (Keune, 2015: 50). We can add a number of probable causes, such as the fact that the commercial area invades all niches of opportunity identified by unions in the area of member support, and can provide a few examples: CARs are competed by private banking and non-banking institutions; the useful tips were taken over by the experts and the advisors of the different companies; approaches based on the direct knowledge of the person are gradually replaced by those having as a source the creation of individual profiles based on software.

\subsection{The emphasis on individualism determined by the "virtual assault"}

Individualism is not increased only by the consumer society, but also by the development of the virtual worlds. People belonging to these generations no longer reject the pressures their parents faced in order to succeed in this world, changing it where necessary, but they have the refuge in the virtual worlds. Technology emphasizes the trends of the consumer society: individuals can now buy different symbolic forms of successes or "alternative worlds" in which easy successes are accessible.

In the virtual world the triplet decision - behaviour - success is broken down: decisions are not definitive, behaviours no longer attract irremediable consequences, consequences are reduced to the status of alternatives.

The access to the people marked by this form of individualism is conditioned by the access of the worlds in which they carry a good part of their existence. Until now, trade unionism has been in conservative positions, persistently maintaining itself in this world. If you do not believe us try to indicate us a digital game that contains union actions! Or indicate the union applications that young people encounter when browsing the Internet! The plurality of the worlds must be doubled by the multitude of faces that unions take in this world. 


\subsection{Work evolution}

Most often estimates of the future of work (and, consequently, of social relations specific to work) miss some unknown facts, such as: a) what will be the changes in the field of consumer behaviours (an important variable for the market economy); b) what changes will the predictions bring regarding the future of work (including the wrong ones) bring; $c$ ) what is the impact that the removal of the human from the work area will have on the consumption (that is, if we can talk about the existence of the economy).

In the transition scenario we can see that globalization has brought with it a new employer reality, the multinationals, respectively the diminution of the power of the states in relation to the multinational patronage and the power macrostructures specific to the globalization (Hyman, 2015: 5). The main effect of this radical change of power relations is the emergence of rentier capitalism and precariat (Standing, 2018). The precariat workers prove difficult to unionize, the unions losing at the same time some of the traditional levers of negotiation with the employer and the state. The robustness of multinationals in the face of traditional trade union actions, derived from their international mobility and the bargaining power with the governments of the different states, generates the obligation of trade unions to build adequate means of action for these new structures. Adaptations to this direction of work evolution require innovation, some possible solutions being discussed in the following sections.

The radical scenario, based on the emergence of superintelligence (SI), takes into account the disappearance of human work, which is replaced by automatic machines/robots. The disappearance of work is consistent with the disappearance of trade unionism and, consequently, of social dialogue, as this is the causal link with the highest probability. But we can think of an alternative scenario: the disappearance of labour could bring trade unionism into the area of actions for human economic rights, thus moving it even more to conservative positions in relation to new technologies. In order for such a mutation to be possible, a number of expectations are needed. The distribution of social rights could be part of the future tasks. The involvement of the unions in the actions of representing the interests of the pensioners tends to suggest the possibility of such an evolution. Each of the two categories of scenarios constitutes simplifications generated by our desire to understand. In trying to get out of the reductionist scenarios area, we analyse below some variables designed to give a more adequate picture of the variants specific to the evolution of the work. 


\subsubsection{The status of the utensil}

One of the essential characteristics for the existence of work is the use of the utensil, in its different faces. From the perspective of the future it can be important to distinguish the existence of two categories of utensils: those destined for production and those destined for everyday use (differentiation is meant to facilitate the explanation of a point of view; we can notice a tendency of increase in the share of ambivalent utensils, the most obvious example being the case of the computer). Both categories of utensils are part of the technologies destines for survival. The utensil intended for production is somehow part of the social dialogue, being included in several types of relations either with the employer (property) or with the workers (attachment, alienation, etc.). The evolution of the utensils is one of the landmarks of the evolution of the work (together with the evolution of the type of specific social relations and, possibly, the evolution of the general context of the society). At the same time, the evolution of the utensils constitutes the fundamental landmark for the evolutionary meaning of history; in the absence of the definite landmarks provided by the utensils, the direction of history would be problematic for many periods.

We have previously indicated (Rotilă, 2018: 47-48) some preliminary guidelines on the utensil, placed under the title Ontological Statute of the Utensil. The analysis perspective was a macro one, discussing in particular the possibility of an ontological leap of the utensil, respectively the variant of the passage from its use by man in order to meet the purposes of survival to the self-existence of the utensil (to be its own purpose). In principle, we can consider that the evolution of the utensils is an evolution of the survival technologies. The ontological leap would suppose a form of survival (based on autonomy) of the survival technologies. In the optimistic scenario, this ontological leap could have two types of consequences: the possibility of taking over human work and reducing the level of human involvement in the use of everyday tools.

Assuming it will reach this point, we have to realize (from a contemporary perspective) that the proximity of utensils to forms of thought and even consciousness is not something entirely new. The long history of the relationship between man and animals used for working purposes could remove one of the scenarios of the future from the area of strangeness. We should worry about the fact that history provides us with some examples of another route, based on the transformation of people into tools, in the form of slaves. The fear of total enslavement of people to new technologies is the greatest contemporary fear of changing the ontological 
status of the utensil. The main problem seems to be the risk of not being able to generate artificial intelligence oriented by objectives coherent with human interests.

\subsubsection{Economic utility}

If we agree with the scenario of continuous growth of labour transfer to machines then the problem is the future of human economic utility. In the context in which the relation with the utensils destined for the production gradually disappears, it is expected that the one with the utensils destined for daily use will remain, taking into account the status of consumer of the human. Will the consumer's economic role be sufficient? To what extent will he survive? What would man have to offer in the economic exchange to maintain production? Suppose we would agree that work (in the sense of human activity) might disappear. But the type of automated activity that will replace it for whom will it be deployed? Who would be the final consumers? We like to believe that people. But who and why would it be interested in maintaining the consumption of a category without productive importance? If such an interest exists then the economic importance of the people will be given by their status as consumers. Increasing the stakes on the economic importance of people as consumers, viewed from a much broader perspective, could be a relevant direction of action of the unions, as the different forms of consumption refusal (meant to affect production) may appear as protest variants.

\subsubsection{Moving part of the work to the leisure area}

We first learned to outsource and transfer the experience through language, then writing, continued by printing and social media forms, so that we can now invent forms of outsourcing and automation of thinking. From the way these innovations changed the work we could deduce some estimates regarding the impact of the future. Only that we find the impact of past innovations post-factum, none of them being preceded by adequate estimates of their social impact.

The best possible prediction at the moment is the one based on the past. However, the past seems to indicate to us rather two types of (complementary) changes: (1) increasing the demands of the "do it your self!" type; (2) the significant transformation of the jobs.

There is a certain increase in the intellectual demands of the individual determined by digitization, which generate a paradox: although we hope that the work will be done more and more by robots (in fact by automated mechanisms/processes, the robots being the symbol of a human 
limit/form to understand, by anthropologizing the models of the outsourcing of the mind called artificial intelligence), we are in a situation of a continuous increase of the intellectual tasks of the individuals. People's lives do not seem to be simplified by technology, but, on the contrary, technology seems to continually increase the degree of complexity of society and the effort required to adapt to it.

Continuous increase in the duration of schooling is one of the relevant indicators. Some of the jobs were apparently lost as a result of technological innovations, many of their tasks being transferred to the area of activities that citizens must do. The replacement of some of the civil servants by the digital technologies brings along with them the increase of the intellectual demands on the citizens, the use of the new technologies tending to turn from possibility into obligation. The tasks allocated by the various services to their beneficiaries are constantly increasing, with McDondalds and Ikea policies being perhaps the most known examples.

\subsubsection{Innovation and trade unions}

There are several possible contact points between innovation and trade unions: the influence of trade unions on innovation in production, the impact that innovation has on trade unions, the ability of trade unions to innovate and take over the solutions offered by innovation. In this section, we address the issue of the impact that unions have on production-specific innovation.

In the field of production, the common place (at least from the neoliberal perspective) is represented by the negative influence of the trade unions on innovation, one of the reference points being the article written by Freeman and Medoff (1984). Some authors point out that there are regional variations in this regard, which seem to be related to the way the society is organized, with Germany being an example of a different situation. For example, Schnabel and Wagner (1994) show that there is no negative influence of trade unions on statistically significant innovation. The countryspecific social model seems to somehow influence the results, partially reducing the image of the trade unions as a brake on innovation. A significant variable seems to be the orientation of the union: if it is strictly oriented towards increasing the earnings of those whom it represents, then the impact on innovation tends to be negative, while the orientation towards employment tends to have a positive effect (Chu, Cozzi, \& Furukawa, 2016). Another variable is the direction of innovation: towards production efficiency (which may have the effect of reducing the number of employees) or towards the product, this increasing the competitiveness. 
At the same time, the new technologies bring with them the ability of employers to anticipate/discover union needs and to act accordingly (by satisfying some, resigning others, compensating by other means, etc.). For example, opportunities for job change may be a strategy for solving the problems that the employee prefers compared to that assumed by the joining of a union.

Our hypothesis is that the situation can be changed if the unions become a source of innovation and followers of innovation in their activity, entering as part of this stream of rapid transformations. In one of the following sections we will indicate some of the possible directions of action.

\subsection{Ideological threats to trade unions}

Nowak (2015: 685) explains the rapid development of trade unionism in the United Kingdom in the first 35 years after World War II in that it was used as a bastion to fight communism. Social rights that have become commonplace in most states during this period have been largely granted out of the desire to use social democracy as a democratic alternative to communism. The reduction of the communist threat followed by its disappearance gave a new impetus to official actions against the trade union movement. Neo-liberalism is the main actor of anti-union ideologies. The belief of the new capitalism, about to be born, is that it can only be consolidated by eliminating (or at least diminishing the power) the unions. In order to achieve this goal, a series of discursive strategies that aim to target (turning them into victims) exactly the citizens who would benefit from trade unionism are used.

Caviar (champagne) socialism is one of the most successful strategies because it uses a difficult to detect bias, based on the following structure: a) no one can get rich from work (the main strategy to set the price of labour at lower levels); b) the representatives of those who work cannot earn more than the average level of the earnings of the representatives (they use an erroneous sense of equality, missing the need for identical conditions); c) moving the egalitarian claims from the relationship with the employer towards the relationship with its own leaders; d) employees can aspire to higher earnings while these expectations are undesirable at the level of union representatives; the gain - regardless of its size - from the business with human resources is considered moral, but not the one the purpose of which is to defend the interests of the same people; e) although they are the managers of private interests and funds (of a public nature), the union leaders are subject to the same conditions of public control as the civil servants. Which shows the intention that the work could 
not be associated in any form to the private area as this would risk a change in the distribution of income. Along with the discrediting of the representatives, the target of these attacks is aimed at diluting the possibilities of action of the unions by their lack of competence: given that both the lack of the necessary resources to stimulate the professionals in the field and the glass ceiling that limits the symbolic rights interfere, the human resource of the trade union organizations is often uncompetitive in relation to that of the employer, a fact visible in the types of actions staged by unions.

Workers' representatives. Opposition to collective agreements only for members and artificial growth (through legal changes) of the importance of the workers' representatives is another direction of action against unions preferred by the neo-liberal ideology.

Use of flexicurity to camouflage work Precariat. Keune indicates a significant change of perspective from the European Union in the sense of weakening the social dialogue, the most important promoter being Directorates-General for Economic and Financial Affairs (Keune, 2015: 53). The key concept in which the precariat of workers' social protection is camouflaged is that of flexicurity. The main anticipated effect regarding such attitudes that are in contradiction with the slogan of Social Europe is the increase of Euro-skepticism among the workers (Keune, 2015: 55).

\section{Trade union policy and ideology}

The work status is related to a significant extent to the ideological perspectives. In other words, the future of work will depend on the development of technology, on social changes but also on political views. Detachment from the Marxist ideology could be a solution, provided that the societies of the future can generate a new model of social balance. In order to have the chance to survive, trade unionism will have to be located in the area of techno-religions as well, promoting the possibility of increasing the individual welfare of those who work (or of those who are not owners) based on technological solutions and equitable redistributions.

In the context of computerization of the society, the reference framework should be changed in order to make work-related assessments relevant. However, the construction of the reference frames is only partly within our reach, being able to use only the discursive/ideological resources capable of influencing the way the society of the future will think itself. But we have no guarantee that long-term influences will be possible, as for 
example, the influence of ideological discourse emerged in the midnineteenth century was exercised for almost two centuries.

\subsection{Class identity}

The strongest ideological engine of trade unionism was its class identity, in its different acceptances. One of its essential features is the opposition to capital, most often embodied by its owners.

Given the existence of few resources for communication, the emergence and functioning of trade unions was largely based on human-tohuman communication, that is, worker-to-worker (activist-to-worker), which was facilitated by the presence of a large number of workers at the same place of work (often for long periods of time), then extended into the habitation of common spaces. The identity found a strong support in coexistence, that is, in the common belonging to the same spaces, activities, etc. In this context, the current isolation of workers is the biggest enemy of trade unionism. Isolation is a physical one, determined by the restructuring of the specific activities of the work, and mental, generated by the breakdown of the traditional social networks, produced by the new means of communication. Keune (2015: 49) suggests that one of the ideological directions of action against social dialogue is the combination between isolation/individualization of workers and depoliticization of relations between work and capital: under the conditions in which the new market model is described as being characterized by an increasing high autonomy of the worker vis-à-vis the collective bodies of representation, as he is "empowered" to negotiate his own rights, this type of discourse is obviously directed against social dialogue. Union solidarity depends on the ability to perpetuate an identity form. The problem is how it can be achieved in the new context.

Authority generates meaning and the powers of meaning generation provide authority. Although the impact of loneliness is increasing, the solutions proposed by unions so far to bring people together in common actions to generate relevant meanings are limited. The trade union movement only succeeds to an insignificant extent to be a source of meaning for those caught in the clutches of the factories of the liberal market economy. Unions should make the discursive leap needed to move to another level of meaning, surpassing the one in which individual freedom, based on faith in free will, constitutes the nucleus of condensation of individual meanings. 


\section{The future of social dialogue and trade unions}

\subsection{Evolution of activities related to the work area}

As we assume the hypothesis of the influence of the destiny of the work on the future of the unions and, consequently, on the fate of the social dialogue, we indicate below some directions of action recommended to the unions, coherent with the foreseeable evolutions in the labour area.

Recognition of new forms of work. The evolution of the demands of the unions on working time, marked by a continuous decrease could be interpreted as suggesting a tendency to 0 . In case of such an option the unions could be considered social institutions relevant only for a certain historical period, their disappearance marking the moment when they fulfilled their role: the elimination of human labour. However, there is an exit from this variant: the introduction into the work area of certain practices that at the present time are not included in this classification. In addition to domestic work, we should also consider the growing number of different types of self-service, which condition the access to certain products and services not only on financial payments, but also on certain behaviours that can be associated with work. We have previously defined them as outsourcing (Rotilă, 2018). Also, all work-for-labour activities can be included (Standing, 2011: 120-121).

The emergence of new forms of work offers more possibilities for their legal classification, the most suitable for trade unions being their inclusion in the labour relations space.

Teleworking. The definition itself reflects the inadequacy to the new of the ones discussing this topic. One of the more appropriate names could be that of e-work. The characteristic of the new type of work is no longer represented by the distance from the place of the employer, but a specific way in which the worker is "where" the activity is carried out. The traditional space-time separation between here and there, work and home is partially cancelled, many of the activities actually taking place in a new space called virtual environment. Where is the virtual environment? The answer to this question depends on the inclusion of new types of activities, some related to the work area.

Freelancers. Updating labour law in accordance with technological changes, having as objective the maintenance of new activities in the labour area, can be a relevant direction of action. In the absence of innovation, the association solutions thought of as alternatives to trade unions, such as those 
built for freelancers, will increasingly enter the social dialogue market, an example being the Freelancers Union in the USA.

\subsection{Evolution of labour law}

There is a mutual influence between the future of labour and the labour law, indicated by the following possible evolutionary variants: the disappearance of the work would make the provisions of the labour law obsolete; a radical change of labour law (in the sense of narrowing the situations defined as work) would cause a de jure disappearance of a good part of the labour. At this moment, a clear direction of evolution cannot be identified: on the one hand we can see a tendency to increase the sphere of social behaviours belonging to the field of work (eg: domestic work) and on the other hand we see more and more productive activities (individual or collective) carried out in other legal frameworks than that of labour (most often civil or commercial law). These two divergent directions of evolution are dependent on ideological perspectives. We believe that dominant ideologies will continue to be the main source for the legal qualification of labour relations. We should perhaps ask ourselves what determines the orientations of different ideologies in order to explore the spectrum of possible evolutions of labour law. However, such an approach exceeds the limits of our topic, with a provisional formal response: the social ideals and the ways in which these are articulated with each other and with the individual ideals.

Unions try to defend a model of balance within a specific type of social relations called labour/work relations. The need for balance will exist as long as this type of social relationship lasts. For the future, a problem could be the fact that although the specific labour law institutions are relatively new creations, they tend to become as inflexible as those derived from Roman law (these being confirmed for over two millennia). The norms of labour law have their origin in political understandings specific to the last centuries, the beginning being given by the Industrial Revolution. For this reason, they are undergoing a continuous recovery. Their character of continuously adjustable social understandings, influenced by the dominant discourse at one time or another, by the political vision of those who come to make the rules and by the growing influences of globalization, generates the need for flexible approaches. Trade union organizations are usually confined to defensive positions, missing the need to keep up with the innovations of the opposing party. The resistance to the new is also determined by the age of those who are part of the decision-making structures, who are often confined in a golden age of social dialogue. 
The biggest challenge for unions is the adaptation of labour law to the new social context. It is unreasonable to expect that labour law will remain unchanged while all the rest of the legislation is characterized by adaptations forced by technological and cognitive development. At the same time, however, changes must be characterized by achieving a balance between the power of employers and workers, thus remedying the strong power asymmetry that characterizes the two parties at the present time. Since we have no evidence to indicate the employers' desire to limit themselves in terms of power, the most reasonable approach is the actions of the trade unions in the direction of increasing power using new technologies and new ideological approaches.

\subsection{Rethinking the right of property}

\subsubsection{Changing the ideological paradigm}

Given that trade unionism will lack viable ideological alternatives there is the risk of its isolation in the area of resistance cells. Modifying the structure of property rights over working entities, based on the historical participation of populations in the birth of technologies and the emergence of innovations could be an ideological direction. It implies a geographical, cultural and historical extension of the meaning of the society, doubled by the support on a relatively new collective entity: humanity.

To the extent that new technologies are based on the collective efforts of previous generations (this character of continuity of progress cannot be denied) retrospective redistribution of property seems a possible legal solution. In other words, the unions will have the interest to push the ownership right towards the whole historical path of humanity, this approach becoming more and more the source of current and future economic rights. A partial argument seems to be offered by D. Zweig (2014), by his attempt to talk about the power of anonymous work, respectively to indicate situations where social success belongs to some anonymous people.

One of the many questions that could open this new approach may be the following: Who owns the rights of property for the ideas taken from the area of collective intelligence, the processing of data provided by millions of people in different areas of activity? The question concerns the nature of the copyright/property in case of crowdsourcing (CS), being one of the present, respectively of the future. At the same time, CS brings with it the quality of symbol capable of clarifying the past from the perspective of property rights. To the extent that (it is shown that) the new is produced by the common contribution, the share of common benefits will be increasing. Corporate social responsibility is 
already a quarter of a step towards recognizing the debts that any kind of economic activity owes to society.

Since knowledge becomes the most important resource, it is natural for it to be treated differently in the context of work-type exchange. This exchange will not be without rest, as the employer's debts will not be exhausted along with the payment of salary and social rights. The knowledge transfer achieved in the work area could be a generator of rights, including for the descendants. The opposite hypothesis would consecrate a class of people who would be the only beneficiaries/heirs of humanity, the mediator of this status being money. Those who find themselves in these privileged positions will not hesitate to try to cancel such a right, this tendency being visible, for example, within the discourses that make the right of property an essential (quasi-biological) characteristic of the humane, trying to deprive any exploration of alternatives from legitimacy. However, it is possible that the charm of the (neo) liberal market economy is due to the alternatives that have contributed to generating the current balance. One of the alternatives (the most important, from a symbiotic perspective) is trade unionism.

A problem in the way of rethinking the social status of knowledge is generated by the absence of relevant trade unions expertise in this direction. One of the reasons could be the fact that the intellectual/intellectual work rarely enters the area of concern of the unions, the proof being the very small number of labour law institutions that correspond to the specific of this activity. The pathos of the union-type generalizations and the preference for speeches addressed to the masses led to the failure to adapt to the characteristics of intellectual activity. It is sufficient to note that the working or time standard does not cover the manner of work of the intelligence in order to find one of the ways in which the intellectuals are crammed into a reality inadequate to the characteristics of their activity.

\subsubsection{The legal status of artificial intelligence}

The future of work could depend on the legal status of artificial intelligence (AI), from the perspective of property rights and labour law. Does AI represent a gradual transfer (and a continuous, subsequent exercise) of human intelligence? If we admit so, we notice that the problem of identifying the subject of law arises: is it the transfer of the intelligence of a human being, of certain people, of a large group (eg members of a profession) or of the whole of humanity?

In this case, the differentiation that M. Tegmark (2017) makes between AI (artificial intelligence) and GAI (general artificial intelligence) is relevant: while AI refers to the forms that it can take in different fields, 
including by using algorithms, the GAI envisions a human model intelligence, capable of learning and being used in a variety of fields, to which we add the possibility of building AI and GAI. From the perspective of social dialogue, the problem is the need to pay attention to the AI objectives (Tegmark, 2017: 54). In this context, the possibility of identifying the AI's objectives with those of its owners is well founded. The likelihood that large companies will project on their own AI which will have social dialogue among values is low.

In the event that the GAI is reached, we would be in a situation of sufficiently high level of development to be able to speak of the possibility of creating sufficient resources for all. Obviously, we cannot foresee the impact of such a liberalization of resources on demographic development. Tegmark (2017: 181) calls this solution "egalitarian utopia", the formula used suggesting its chances of success. Gradual approaches, however, may change the perspective. We can imagine the community or even states that become owners of an AI, respectively the results of its activity. The contribution to knowledge could be one of the regulators of the new form of property.

For the situation of the appearance of the GAI or even of the AI, there are also additional variants of the type of sharing of the components underlying it, respectively of the property right. For example, the very high computing power required by AI could be ensured by a number of joined resources. Or, its essential support could be a form of thinking together of the members of society.

\subsubsection{A few preliminary steps}

Awareness of the problems that AI can generate has led to multiple attempts to anticipate them. The Asilomar Conference had a significant result, the Asilomar AI Principles document being elaborated. The extent to which the principles established at Asilomar can combat anticipated risks (without discussing the unforeseen ones) remains to be discussed. An example of risk is perverse instantiation and infrastructure profusion (Bostrom, 2014). The solution seems to lie in the possibility of a logical combination of these principles in a complex model, which will ensure appropriate mutual weights and relationships. Such a model should be incorporated, for example, in an ethical module compulsory for any artificial intelligence, a kind of "soul of AI" that would generate the directions of orientation to the new form of existence.

It is relevant that the Asilomar AI Principles also include the following: "14) Shared Benefit: AI technologies should benefit and empower as many people as possible. 15) Shared Prosperity: The economic prosperity 
created by AI should be shared broadly, to benefit all of humanity." They indicate the availability of accepting social values as fundamental to human existence, thus opening a window of opportunity for the social future (the most commonly discussed implementation variant is universal basic income). Turning the possibility into reality depends on the capacity for involvement and participation of the unions in thinking about the future. Reducing trade unions' concerns about the impact of AI to a few theoretical studies, which either calm workers or alarms them in an exaggerate manner, is an inappropriate approach to the problem. In our opinion, the right way is the involvement of the trade unions in the use and development of AI and new technologies, respectively in the profile research, because it offers an adequate grip on the new world model and places the trade union movement at a relevant level of power and social influence in order to still be able to determine the respect for the principles of social dialogue.

\subsubsection{Technology could generate an increase in solidarity}

The idea that technologies are extensions of the self must be rethought, its meaning being that of proximity to intersubjectivity. Technologies significantly reduce the differences between individuals, thus redefining the self in the area of its common contours. From another perspective we could consider that each technology determines the appearance of spaces in which each self can expand. But even in this variant, these spaces have a common structure, which generates forms of extension standardization. Extensions standardization influences the appearance of self-standardization. The natural differences generated by the genetic evolution/variation tend to be cancelled by the cultural evolution aimed at increasing cohesion. Increasing cohesion could lead to a higher likelihood of solidarity-based actions.

\section{Some future solutions for trade unions}

To the extent that viable alternatives to democracy and solutions to complement its specific representation mechanisms are missing, we tend to consider that trade unionism will survive because it constitutes a deflection and representation valve accessible to those who work (the hypothesis is consistent with maintaining human work). However, we do not know the form it will take, the predictions based on the expectations of the professionals in the field going rather towards the conservation of the current structures (a fact that betrays a bureaucratic tendency) rather than on the solutions to adapt to the increasingly obvious changes in the labour 
market and in the area of social power relations. In some cases, there is also a problem concerning the democratic legitimacy of the trade union organizations, as long as their contamination with the nomenclaturebureaucratic type of mentality is visible. Remaining in the area of Marxist ideologies could be one of the causes of the unions' positioning in forms of structuring and action specific to the industrial era. The reactive orientation indicates the break in the direction of progress. At national level, the perception is that European trade union organizations, for example, tend to become a true copy of the EU bureaucracy, losing the ever-changing needs of those they represent.

Inadaptation of trade unions can be seen, for example, in the low level of unionization of young people (beyond the additional effect generated by the high share of unemployed among young people, the effects of precariat work and the preference for individual bargaining solutions), the trade union organizations being insufficiently prepared to adapt to their expectations and behaviours (of the two optimal ways of matching the young worker to the union and the union to the young worker, only the first one works). Even in the few situations where the low weight of young people is accepted as a problem, the solutions used are rather out of form, as they are generated by approaches on a bureaucratic model: setting up youth commissions, seminars for young people, choosing a few young people in some management structures.

If it can make the necessary adjustments, as long as work exists, unionism has a chance to survive. However, the existence of human labour may not be sufficient, as there is a need for something extra, respectively what Marxism indicated as class consciousness. However, the old ideological paradigm seems to be accelerating into disuse, the traditional working class being replaced by a so-called precariat crowd (Standing, 2011) that has not yet reached a class consciousness and we do not know if it has any chances to reach this level in the future. The fact that the unionization is not effective in the area of activities characterized by a high level of isolation and in the area of freelancers could be an indication. Unionism, already strongly affected by the individualism generated by the current form of the market economy, must face the effects generated by the emergence of precariat.

\subsection{The power of unions}

The power of trade unions is the main argument for their status as a social dialogue partner. To the extent that this hypothesis is correct, the solutions for maintaining or even increasing the power of unions can be considered as contributions to the survival of social dialogue, applying the 
rule: the more power (of the unions) the more social dialogue. Social dialogue implies a partnership relationship between the main social actors. It is expected that each of the parties will try to change the definition of the partnership. From the perspective of the social dialogue the excess of power of the unions has some risks as compared with the excess of power of the employer. Therefore, there is a limit to the power of the unions, beyond which the balance risks being broken. However, the main problem of the future is the impossibility of reaching the balance area, not exceeding the limits of power.

We will discuss below some of the variables specific to the power of the unions, presenting some of them in a synthetic form and others accompanied by additional details.

The bargaining power is defined by the following variables: (a) the social importance of the represented; (b) the social impact of their protests; (c) the capacity to mobilize members; (d) negotiation skills.

The discursive power consists in the ability of unions to impose legitimate social discourses, through which it defends the interests of the members and presupposes the control of communication with its members, potential members and the general public.

\subsubsection{Financial power}

From a financial perspective, the power of unions is not evenly distributed. The differences between the current power of different unions can be perpetuated. It is sufficient to look at the financial strength of some of the unions in the western states, generated either by their own economies or by the management of social funds, and to refer it to the organizations of Eastern Europe to get an idea of these differences. A solution to balance the financial power is the financing of the unions. However, it can be both a support solution and a weakening method. If the funding is not focused on programs that determine the development and take-up of new technologies, it is likely to be inhibitory because the union activists, as they see their means of financing their personal income secured, will no longer be stimulated to act and innovate.

\subsubsection{Economic power}

The economic power is given by their status as market investors and by the economic role outside the work that the members and unions have. An example of action that can be carried out by unions based on economic power is the solidarity of the buyers. Work-based solidarity has proven profitable in the last two centuries for those who work. Even if the 
technology calls into question the existence of work, there is an additional solution to save it: the solidarity of buyers/beneficiaries. The orientations towards the replacement of human labour as a solution for the optimization of the profit come from an inevitable limit of this type of approach: the profit depends equally on consumption and the consumption depends on the purchasing power of the population. Given that workers have the quality of buyers as well, actions based on different abstentions from consumption as forms of protest could be successful.

At the limit, the consumption of "non-human" products and services could make up the new dimension of ecology. In turn, the strategies that take these forms of protest into consideration face another limitation, namely shifting the focus from workers to freelancers.

\subsubsection{Information power}

The information power is generated by the access of unions and their members to information. We will illustrate here only one of its approaches, namely crowdsourcing, resuming the problem from a broader perspective within the section on cyber unionism. Crowdsourcing (CS) is the most important trade union resource from a cognitive perspective; if we agree that knowledge means power then the CS can be considered part of the most important resource of the trade union organizations. In principle, the use of the CS is not a novelty for the functioning of the unions, as the current social rights can be considered as having their source, for the most part, in this form of collective thinking. The mention of CS as a resource, however, takes into account the fact that technology creates opportunities for more efficient use, which can lead to the emergence of true cognitive communities.

\subsubsection{The ability to change and innovate}

Investing in knowledge is the orientation necessary for trade unionism in order to survive. Informatics seems to be one of the areas in which trade unions should specialize urgently. To understand this need, you just have to try to answer this question: Have you seen any union IT application? Not even IT unions seem to be interested in such approaches. Although there is a wave of solidarity-based actions on the Internet, unions miss organizing in this virtual dimension. These examples say enough about staying behind trade unionism.

The conservatism of the unions, determined by the inability to adapt to the new one, generates the loss of opportunities, endangering the existence of institutions of social dialogue. Possible forms of action and 
protest, such as forms of work, have far exceeded the frame of thought of relatively recent laws. Their use lies not only with the capacity to innovate the trade unions and the solutions made available by the new technologies, but also with the new social and political sensitivities.

From the perspective of interventions that would give a real chance of survival to trade unionism (and, hence, to social dialogue), we share the idea attributed to David Rolf regarding trade unions: "innovate or die" (Kelly \& Tomlinson, 2016,: 12). Given that the probability of future battles taking place on the field of knowledge is high, it is clear that trade unions need to be oriented towards approaches based on knowledge and those that generate cognitive power.

Although it may seem ridiculous at the moment, a future fight solution of unions may be to strive to improve the cognitive features (possibly other relevant features in terms of work or property) of their members. Owning AI modules, robots or transforming them into cyborgs should not be excluded from the outset, their relevance being given by the contexts that the future will provide.

Two essential innovations have generated effects whose impact on trade unions and social dialogue is insufficiently determined (or determinable): Facebook and the smartphone. One possible effect: both have caused the communication channels to multiply together with the increase of the level of effective isolation. Unconscious isolation is an impediment to unionization. An exception could be the movement of trade unionism in the space of the presence of the working citizen: online/virtual space.

\subsubsection{Building communities}

Solidarity actions can change the face of some of today's technologies. We can easily imagine the effects of a "trade union for Facebook" organized globally, which will generate an autonomous (largely) social bubble from the perspective of online socialization. At the same time, however, online union tools must support the construction of effective communities, with the online community having to be duplicated by real forms of community. We know, for example, that physical loneliness becomes pandemic, generating multiple negative effects (Cacioppo \& Patrick, 2008). Traditional trade union solutions to bring people together in the same spaces, allowing them to see, touch and generate existential references to each other, will continue to be effective, at least in the near future. However, they entail the waiver of actions meant to fill the time and 
to reaffirm past meanings in order to allow the transition to those useful in the new context.

\subsection{Partnership}

Partnership is a special form of social dialogue within which unions strive to harmonize solutions for defending the rights of employees with those aimed at the efficiency of the enterprise. However, this strategy needs to be approached cautiously, as the partnership is often part of anti-union speeches. For example, Robert Taylor (2001: 10-11) considers that partnership at work is one of the strategies of adaptation of the unions, as these must demonstrate the added value that their existence brings to the company, improving competitiveness and financial performance as objectives that unions have to assume. Given that Taylor combines partnership with the disappearance or at least diminishing of the role that collective bargaining plays in the existence of unions, it is obvious that the way Taylor understands partnership is part of the vision of preserving a rather formal role of unions. The use of the partnership is consistent with maintaining social dialogue only if it brings win-win solutions, the balance of power between the two partners remaining in a state of balance.

\subsection{Provision of skills}

Changing more jobs throughout your life will increasingly move towards the change of more professions. Under these conditions, one of the essential forms of help might be the support for learning to learn, as this is part of cultivating mental flexibility in order to support adaptation to change. The use of applications and smartphones in the learning process is constantly increasing. The new approaches in Digital Learning 2.0 will be focused on building skills through application of knowledge (Kang, 2019).

An implicit activity of the unions is the adaptation of the members to the new technologies by their use in the union activity. The lack of investment in this area indicates a lack of vision. To the extent that the actions carried out with own members use communication channels and online tools, these can contribute to increasing the ability of members to adapt to the use of new technologies.

\subsection{Cyber unionism}

This section could have as its motto the formula what it should be, indicating the directions of development of trade unionism that we consider appropriate for the purpose of its survival. Cyber unionism is one of the possible formulas for the set of proposals, as it oscillates between the idea of 
a radical change of trade unionism and the gradual introduction of new directions/instruments of action. Because, in the scenarios regarding the evolution of artificial intelligence, the model of the transition from one stage to another has a significant probability, we will focus on the gradual introduction and use of new technologies in the trade union activity.

Adapting the unions to the new technologies could be considered an ongoing process. For example, Kelly and Tomlinson (2016) point to a series of actions already undertaken by different trade union organizations towards the use of new information media, one of the solutions that caught our attention being online platforms in order to aggregate the experience of workers and to act against those who treat them illegally incorrectly (Kelly \& Tomlinson, 2016: 13). Although, at first glance, we might consider that things are moving in this direction, the observation that these are just isolated examples may be just as appropriate.

There is a question to which we cannot give a definitive answer, but only a probable one: are trade unionism and social dialogue compatible with the takeover of new technologies in the operation of these institutions? We can easily imagine a software meant to instantly consult all workers in an enterprise or a state on one of the possible decisions, thus replacing the consulting part of the social dialogue. If this tool takes the form of an online social network, allowing the aggregation of opinions and positions towards the proposals of the company or the state, the proximity to the structure of social dialogue will be even greater. At the same time, however, such an instrument is more likely to be developed by unions, representing much of the online dimension of these organizations. The final decision in this regard will take time, as we are limited to scenarios with different probabilities (updatable/updated depending on the route on which the development of new companies is registered).

What has digitalization and the Internet brought to socialization? Often, we tend to believe that only an increase in irrationality and manipulation possibilities, missing the new dimensions of socialization and communication. New technologies bring along with it for trade unions the possibility of creating their own channels of communication, of developing new dimensions of interaction with their members, the shortening of consultation periods, crowdsources for trade union organizations. The existence of online social networks can be used as an adjunct to traditional social networks. Standardizing procedures and disseminating them online can amplify the impact of union actions. 


\subsection{Online union services}

A young man using his smartphone, on average, approx. 40-50 hours per week can hardly be interested in organizations based only on old socialization and action models. He spends most of his time in the online environment, his attention being influenced by the characteristics of the entities in that space. Also, the desire of the workers to work a variable number of hours, according to their own decision, comes along with the desire to access the union services at any time. We discuss about a new way of being in contact with the workers, the unions having to comply with this type of "being at hand continuously".

In an ever-increasing flow of information, the ability to identify relevant information, separating it from noise, represents a useful feature for unions. Establishing their own information flows, using the verification and selection according to the truthfulness and the sphere of interest of the members, can prove to be a useful union service.

Online trade union service packages can be offered through trade union platforms. Their emergence offers at the same time new opportunities, as to a large extent the contribution can be replaced with the sale of advertising and specific Big Data information (at least for some categories of members) and with the mass contracting of some services (for common gain, syndicates-members, by dividing the discount).

\subsection{New forms of protest}

The idea of innovative protests assumes four dimensions: (a) innovation within the game space created by the legal provisions; (b) the use of no man's land generated by technological evolution; (c) introducing forms of protest that force the law or even contradict it; and (d) "neo-Luddism".

\section{a) Innovation within the limits of the legal space}

As more and more portions of public space become part of the virtual space, it is clear that unions can also protest in this space. The condition is the ability to innovate and/or take over the good practices in the field. Solidarizing workers on social networks around a set of ideas, online petitions and online collective expressions are just some of the ways of action already developed by some trade union organizations. Two fundamental guidelines are needed in order to hope for a relevant degree of success in this field: the use of research and the control of speech through the use of one's own communication channels. 
Change of workplace as a protest. The scale of communication brings with it the multiplication of solutions to find new jobs. Changing the workplace/resignation could slip in the area of new forms of protest. If all these actions were mediated by the IT solutions of the union then they could benefit from their organization and use as forms of protest.

b) Cyber protest. In the context of new technological developments and their impact on socialization, the rules established by the law in the field of protests are already outdated. Cyber protest is the variant for cyber war unions. It involves using a whole range of opportunities, many of which are mentioned in this article.

\section{c) Introduction of new institutions/actions; pre-legal phase}

Democracy is constantly reinventing its mechanisms necessary to ensure its survival, sometimes new institutions going through a phase of illegality before enjoying legal legitimacy. Where unions fail to identify new directions of action, people do so in different forms of association. The observance of the rules of the game is rather a problem of discourse than of the law, especially when the interval created by the legal interpretations is either too narrow or too wide.

\section{d) "Neo-Luddism"}

By the term "neo-Luddism" we suggest the specific actions meant to defend the life span of some of the professions, respectively the period in which they are exercised by the people. Although the concept of Luddites is often used in a negative sense, indicating the (pointless) opposition to progress, we cannot exclude the possibility that its new form, meant to defend certain human rights, is relevant in relation to some of the possible contexts in the future. At the limit, it could become an essential concept for defending human rights. Even if "neo-Luddism" is not going to be used as a strategy of action by the unions, attitudes consistent with its meaning already exist and will be observed more and more often among those affected. If it is not used by trade unions then it will be used by politicians, with the risk that they will use it for different purposes.

Given that the degree of resistance of professions to changes caused by technology is highly variable, we can expect that many of them will develop more and more strategies to defend the interests of those who are already part of them, considerably limiting the access of new people. Numerus clausus could be the dominant model. The confluence of the forms of defence of the different professions could lead to conservative policies, although in the context of globalization they may have a limited impact over time. 
As data becomes more and more valuable, the instructions for their protection prove useful. Data protection belonging to the members of a profession can lead to the increase of the life span of that profession in the labour market, delaying the appearance of the machines.

\subsection{Data processing}

Adapting to Big Data involves supplementing democratic mechanisms of information processing, based on distributed processing (specialized networks process the types of data relevant to them), with centralized mechanisms, capable of processing as much information as possible to indicate timely decisions. This evolution of the social context suggests the necessity of adapting the functioning of the unions to the changes of the society, based on the use of the new technologies of information processing. An argument is also the fact that the speed of change of the society and of the individual options is much too high at the present time for the old mechanisms of information processing (democratic decision-making mechanisms) to be sufficient on their own.

The absence of the necessary structures to collect Big Data-type information relevant to the trade union activity and the ability to process such data leads to the inability to make appropriate decisions and to produce meaningful visions. We can see the failure of both decision networks and of those meant to produce meaning (they can in many cases be exactly the same networks.)

Personalized interventions. Union solidarity will require additional ingredients in order to be perpetuated. In the new IT context, unions have the possibility to set up and follow the trade union history of each person. The trade union history includes the individual route within the trade union organization. Introducing a "trade union path", containing hierarchies and steps that can be followed depending on seniority and involvement in the organization's actions, could increase the degree of membership of the trade union organization. Such an approach could remove trade unionism from the area of opportunistic decisions, without long-term consequences, moving it closer to existential decisions.

It is relevant that the use of new technologies in daily life alters the desires of the union members, as they expect from the unions a level of anticipation of the needs that they have similar to that demonstrated by the big companies. Knowing the expectations and desires of the members, individually and collectively, becomes an essential condition that the new trade unionism must fulfil. 
In the context in which the new technologies allow the creation of the profiles of the union members (obviously, with their agreement), it becomes much easier to use the personalized approaches from the unions, thus responding to expectations in this respect identified in the research (Tait, 2017: 3). The extension of this area of the knowledge of its members carried out by the trade union organizations gives them an increase of power within the social dialogue relations.

\subsection{Trade union research}

In a world where knowledge is power (and essential economic value) union research is almost absent. Moreover, even the few union researches are mostly focused on different issues than those raised by the new social challenges. Although in some cases they have financial possibilities, the unions are not interested in risking some of the revenues to finance research in the field, thus missing the possibility that some of these researches will generate useful results. The paradigm shift and the entry of unions into the research-based knowledge competition optimize the survival chances of these organizations.

\subsection{Reducing operating costs}

Like any democratic mechanism, the activities that ensure the functioning of the unions are time and resources consuming. While in the case of political parties the costs assumed by the functioning of the democratic mechanisms are borne by the state, in case of the unions these costs significantly dilute the resources of the organizations. The use of new technologies could lead to a reduction of costs, the essential condition being the preservation of democratic standards.

\subsection{The construction of trade union artificial intelligence}

Not every AI solution fits in any context, the identification of the right solutions for the trade union interest depending on the trade union intelligence. The main image of artificial intelligence known so far is the neuromorphic networks based on self-learning. The basic condition for their development is the provision of relevant information. The information relevant to the trade union activity can be found in the "trade union world". In order to understand this dimension of social existence, artificial intelligence should be trained first to ensure that timely solutions to problems faced by unions are identified. Opening the context and presenting the different packages of measures will belong to people. It is not excluded 
that the initial trainings of the AI will be the defining ones for its future evolutions. Which means that the absence of orientations specific to the union objectives in the information structure with which an emerging AI is "fed" would deprive it of the interest for this dimension of social existence. If they want to remain competitive on this variant of progress, unions will have to start building their own AI models.

\section{Are trade unions necessary?}

The main topic of this article is the future of social dialogue. We wonder if social dialogue is going to survive in the future, and at the same time, whether it should survive. The answer to the first question is largely dependent on the answer to the second. The survival of some social institutions has a significant degree of dependence on their social utility, respectively on the people's desire for them to survive, a desire transformed into a political will. The most important scenario that we analyse in this article is based on the positive answer to the second question: we believe that social dialogue should survive. This means that we do not deal with the rest of the variants (which does not exclude different degrees of probability regarding their occurrence).

We use an additional presupposition: social dialogue is possible only under the conditions of the existence of unions. The only hypothesis that seems to indicate an argument in this regard is the establishment of the following correlations: a) the existence of a global correlation between the evolution of trade unionism and the evolution of social dialogue; b) finding a correlation between the evolution of social dialogue and the distribution of incomes. Thus, we can see that the reduction of the social dialogue and the power/importance of the unions is correlated with an increasing concentration of the incomes.

However, the correlation does not show causality, having to consider a whole series of other variables that could have acted causally. At the same time, however, the potential existence of other causes does not reduce the probability of the first explanation and does not remove the problem: the income share of those who work is becoming smaller. This great current problem can turn into a tragedy in the future. The traditional solution to this problem is the redistribution mechanisms required by the social dialogue performed by trade unions or those voluntarily initiated by states. If the redistribution is not established through a dialogue, it carries along with it the risk of new inequities. In this whole argumentative chain, some 
weaknesses are visible, that is, variables that can change the direction of evolution of history at any time:

- The assumption of axiological stability over time. It involves faith in defending current social values in the future. But history shows us that we are far from consistency, the speed of evolution of technologies accelerating the speed of axiological changes as well.

- The idea that there is only one solution to a social problem. Trade unionism may not be the only solution for the survival of social dialogue. It is sufficient to read, for example, the solutions proposed by Paul Kirby (2016: 39-42) to observe that right-wing ideologies are already advancing alternative proposals aimed at accentuating power asymmetry. It should be noted that Kirby implicitly recognizes that a society without social dialogue is not possible. Its model implies rather what the trade unions call "formal social dialogue" or, in more appropriate terms, the reduction of social dialogue to the one of enterprise, carried out with partners lacking real bargaining power. It is another chip given to the "employees' representatives" solution, which has already caused significant damage to unions and workers, destroying social dialogue. Kirby actually reaffirms a specific reality of the last two centuries: the main feature of the patronage heaven is the absence of unions. The fact that the consequences of this patronage dream, which is becoming more and more reality, are difficult to be observed by workers is one of the traditional threats addressed to the unions.

\subsection{Social utility on trade union costs}

The functioning of the unions can be associated with a number of additional social services that these perform, which are of benefit either to the society as a whole or to communities larger than those constituted by its members. The unions participate in the diversification of the mechanisms of representation of interests. The multiplication of the mechanisms of dialogue also comes in support of democracy. In most states the costs of these social services are borne by unions. If we compare the unions with the political parties, considering that both have their social utility in a democratic state, we will see that while the political parties benefit from the financial support of the state, there are few states that choose to financially support the functioning of the unions. The social utility of trade unions can be demonstrated by appealing to the eidetic reduction, specific to the phenomenological method, that is, observing what happens if we eliminate the unions (or if we diminish their power/social role). 
The effects of the lack of unions. Along with eliminating the continuous representation of entire categories of citizens with an important economic role, in the absence of unions/union actions, the capacity to relieve situations through small conflicts decreases. Thus, tensions accumulate, among the potential effects including either the larger conflicts or the throwing of the workers in the direction of the different proposals from the political market, many of them being extreme.

Thatcher effect in the case of Brexit (the significant reduction of unionization has generated isolated, easy to manipulate workers) is an example of the long-term effect of diluting the contribution that unions have to the functioning of democracy. It tends to confirm a worrying hypothesis: the fewer institutional mechanisms for dialogue and representation, the greater the possibilities for citizen manipulation. The problem is not only generated by the emergence of new technologies, but also by the removal of citizens from the traditional forms of socialization and representation.

\section{Possible evolutionary variants depending on different hypotheses}

In the attempt to provide some clear indications regarding the possible variants for the future of social dialogue, we operate with several working hypotheses, constructed according to the variables that we consider as having the highest probability.

\subsection{Slow emergence of artificial intelligence. Transition variants/for short and medium periods.}

Along with the directions of technological development with the highest probability, this variant of work places in the foreground two variables: ideological evolutions and the ability of unions to use new technologies. We believe that the following scenarios should be considered:

\subsubsection{The pessimistic scenario}

Emphasizing the ideological turn that made individualism possible and emphasizing the asymmetry of income distribution. It leads to the disappearance of social dialogue, determined by the very high concentration of economic power and the decrease to the minimum possible limit of state power. The scenario is largely in line with Hyman's (2015: 5) From Bad to Worse, which includes emphasizing power asymmetry. The monopoly over AI would lead to the seizure of all power by the owner. In relation to the power of the unions to mobilize the workers it is sufficient to imagine a mechanism of the type Cambridge Analytic, with a much greater operating capacity, within the reach of those who have the economic power, in order 
to have an image on the power asymmetry which the unions are already facing.

\subsubsection{Moderate scenario}

It is based on the partial balancing of the balance of power, with the main causes being the gradual adaptation of the unions to the new technologies and the emergence of new ideological currents, meant to question the fairness of the distribution of income. The specific evolutions of this scenario have been outlined in part in the different sections of this article.

An alternative that can be considered is the replacement of the specialized software unions, the social dialogue being transformed into a standard mechanism used for any public and enterprise policy. For the ideal option, these automatons should ensure the compliance with the essential condition of mediating the power relations between two social poles, ensuring a continuous balance. In this variant we could consider that the trade unionism would disappear by fulfilling its fundamental objective: establishing a perpetual social dialogue, which would determine the fair distribution of income and respect of the fundamental rights of the employees (which we can assume as being in a continuous transformation).

\subsubsection{Optimistic scenario}

It implies a significant balancing of the power balance. In this variant, we assume that the unions manage to access the new technologies and to implement new approaches, including the representation of the precariat workers. The main form of representation of the precariat workers is the unions. Increasing the fairness of income distribution and ensuring the universally guaranteed minimum income as a reserve in the face of the effects of technological development seem to be optimal solutions. It includes the development by unions of the specialized software mentioned in the moderate scenario, as part of them.

\subsection{Rapid emergence of superintelligence (SI): variant of technological singularity}

In this variant, the fate of social dialogue is dependent on the destiny of humanity. Even if it has a low probability, the social dialogue with SI might arise (assuming the inclusion of SI in the society). In other words, we cannot exclude the possibility that social dialogue may in the future reach the form of dialogue between people and SI. It is one of the possible scenarios, even if not very desired. If SI reaches this level of power, however, the existence of social dialogue may be a joy to us, one of the discourse topics of mankind 
becoming contoured around the formalism of this type of dialogue (continuing the present model, in which the unions complain frequently due to the formalism of social dialogue).

It can be difficult to imagine the forms of pressure that people might exert on an SI capable of producing anything. However, most scenarios on this topic tend to miss an essential aspect: we do not know how humanity will change in the context of a very large advance of knowledge. In other words, models based on the exponential growth/ explosion of artificial intelligence and on the linear/historical development of human intelligence might prove wrong. One of the variants of intelligence development is the emergence of a collective intelligence, based on much more advanced individual intelligences. We therefore suggest that such a dialogue will not take place between an SI and people with the current level of collective intelligence. Obviously, we cannot exclude the variant in which SI is actually collective intelligence, based on a higher level of intelligence aggregation (made possible by technological solutions). In all these alternatives, solidarity and the systems that can support the coordination of citizens become important values.

\subsection{Multiple thresholds}

Theories on SI often miss one of the variants that we can define as the multiple threshold theory: the possibility that the (conscious) human mind is only one of the multiple thresholds existing in the path of total intelligence. In this variant SI is reduced to an intelligence superior to the human, but without reaching in a single leap a form of lack of limitation.

The theory of intelligence intervals/multiple thresholds has a significant probability if we look at the evolutionary path of intelligence and if we consider that it was dependent on the laws of physics. To the extent that we assume the perspective of intelligence intervals, the most known predictive approach so far regarding the evolution of intelligence (artificial or natural) is the Bayesian one, based on updating predictions from the perspective of the latest knowledge, adapted to the characteristics of each stage. In other words, the predictions of the third stage in the evolution of intelligence are dependent on understanding the intermediate stage, redefining the spectrum of possibilities. The possibility of this variant brings with it the question of whether the social dialogue remains possible on the next intelligence interval, the attempts to clarify on the possible, anticipated coordinates of it, being relevant. 


\section{Conclusions}

The survival of social dialogue is dependent on the extent of social change. There is a significant number of future scenarios that would make the discussions about social dialogue obsolete. Even if not many, there are scenarios that carry variants of maintaining some of the current social structures, the social dialogue having chances to be part of the area of institutional continuity.

If the bypothesis of the social brain is correct, that is, if the evolution of the human brain, respectively of the human mind has been largely dependent on social relations, and if work occupies a significant place in social relations then we can consider that work is part of the types of social relations that have essentially contributed to who we are. In this case, eliminating work brings with it the risk of modifying something essential in the definition of humanity. As long as humanity lasts, so will work. However, in this sentence we consider humanity as we know it, from its current forms and its historical path, making it difficult for us to deduce the future modalities or even to offer guarantees regarding the persistence of humanity.

To say that work will continue to exist does not mean that it will have the exact same meaning as it does today. It is enough to look at the past to understand the many changes of meaning that history has brought about in relation to work. However, this may also mean that the human's transition to something else, to another existential modality, no longer guarantees the persistence of work, the problem being represented by the types of social relations that will be established in the case of another way of being.

If we accept that social dialogue is one of the forms of supplementing the deficiencies of democracy then we have to accept that the maintenance of social dialogue serves the interests of democracy. In this argumentative framework, we must consider that one of the useful alternatives for the future is not less social dialogue, but more social dialogue (which could also imply the formula: not less unionism, but more). Such a variant may offer a counterbalancing solution to the continuous increase of the concentration of property in the hands of a few people, General Artificial Intelligence (GAI) or SI. The recommended path is the involvement of the trade unions in the use and development of AI, respectively of the new technologies and of the research of profile, because it offers an adequate grip on the new model of the world and situates the trade union movement at a relevant level of power and social influence in 
order to be able to continue to determine compliance with the principles of social dialogue.

We cannot exclude the possibility of diluting the usefulness of the unions due to the birth of new pseudo-union forms of organization, in the first place in the hierarchy of the probability of occurrence having the movements triggered to solve specific problems (grassroots movements being an example in this sense), followed by surrogate models from the neoliberal area.

Uncertainties regarding the future of work are automatically transformed into uncertainties regarding the future of trade unionism and social dialogue. In addition, trade unionism is also threatened by the dangers posed by its inadequacy to the new social environment. In such uncertain conditions, the key term is probability, the fundamental question being that on the probability of the trade unionism survival. Since we discuss about a space of the social, the probability of perpetuating trade unionism (as a form of guarantee of social dialogue) is not already given, being dependent on the actions that the unions will take to improve it and the development directions that the societies will adopt.

The use of the phrase cyber-syndicalism has a metaphorical purpose, meant to open up to the multitude of solutions complementary to the traditional actions. We believe that the solution of interpersonal relations lies next to the "technological extreme". In other words, trade unionism has a chance in the future if it succeeds in combining new technological solutions with the preservation and development of traditional social networks that have previously ensured its functioning. In the context of the estimated emphasis of individualization, trade unionism could gain ground through the possibilities it opens up for maintaining interpersonal relationships, contributing to the healing of citizens from the specific loneliness of this era and probably of the future ones. Trade unions must embrace change, also orienting it in the directions appropriate to their purpose. To the extent that the need for trade unionism can be sustained, as a form of perpetuation of social dialogue, the solutions we propose could prove useful. To the extent that solidarity will matter, trade unionism could survive, and along with it, social dialogue could be saved too. We don't know if or how much it will be able to do. It is, however, dependent on a political perspective. We move on sands, lacking the motives of optimism regarding the future of trade unionism and, consequently, of the social dialogue.

If the state continues to be a guarantor of social systems, its concern for the future could materialize in a diversification of social dialogue institutions. The decrease of the social importance of the social dialogue by 
diminishing the role of the unions also reduces the probability of introducing a system of redistribution (income and/or property), in the variant of a major impact of the artificial intelligence on the labour market. If we estimate future developments based on current trends, increasing the polarization of society seems most likely. Which means that giving a chance for a fair distribution of wealth (or even livelihoods) in the future implies a reversal of the evolution of this mechanism. Increasing the role of unions in order to enhance the importance of social dialogue seems to be the logical solution. But waiting for this growth to be initiated or at least supported by the state is not a rational approach; even if this happens, the probability of negative effects is higher than that of positive impact. The solution is rather a reform of the trade unionism based on a new ideology and on the increase of power due to the use of new technologies. We think that the competitiveness of the unions in the current market of information and power is the most appropriate option.

If these arguments are not sufficient then an alternative must be considered: the absence of a gradual and democratic intervention in support of equity, such as that promoted by unions, risks giving rise to extremist ideologies. If we consider that trade unions are advocates of social rights obtained through social dialogue, then paraphrasing Taleb's (2018: 18) phrase, "It is better to complain about trade unionists, than about their lack!!", would illustrate a social rule

The scenarios proposed in this article go beyond an obvious limit: they explore the possibilities of evolution of the society using possible solutions to meet our current goals. The solutions discussed do not take into account the change of the wishes of the people in time, being impossible to anticipate the directions of evolution of the objectives of humanity. We cannot exclude the possibility that any significant change generated by technology will cause appropriate adaptations of the values of humanity. This is a weakness commonly encountered in such approaches, the current scenarios being vitiated by contemporary axiological perspectives, as these most often aim to respect the current structure of values. However, one of the fundamental questions regarding the future concerns the changes it will generate in the ideals of humanity. Our concern for the future must take the form of care for the possibility that future generations will fulfil their own ideals. Based on the current social norms we tend to prescribe the social dialogue to the citizens of the future, but we cannot be sure that this will be part of their expectations. 
The Future of Social Dialogue in the Age of Artificial Intelligence Viorel ROTILĂ

\section{References}

Bostrom, N. (2014). Superintelligence: Paths, dangers, strategies. New York, USA: Oxford University Press.

Cacioppo, J. T., \& Patrick, W. (2008). Loneliness: Human nature and the need for social connection. New York, USA: W.W. Norton Co.

Chu, A. C., Cozzi, G., \& Furukawa, Y. (2016), Unions, innovation and crosscountry wage inequality. Journal of Economic Dynamics and Control, Elsevier, 64, 104-118. doi:10.1016/j.jedc.2015.12.004

Freeman, R. B., \& Medoff, J. L. (1985). What do unionale do. Industrial and Labor Relation Review, 38(2), 244-263. doi:10.1177/001979398503800410

Harari, Y. N. (2016). Homo deus. A brief history of tomorrow. New York, USA: Random House.

Harari, Y. N. (2018). 21 lessons for the 21st century. London, UK: Jonathan Cape.

Hyman, R. (2015). Three scenarios for industrial relations in Europe. International Labour Review, 154(1). 5-14. doi:10.1111/j.1564-913x.2015.00221.x

Kang, S. Y. (2019, September 2019). To build the workforce of the future, we need to revolutionize how we learn, World Economic Forum. Retrieved from https://www.weforum.org/agenda/2019/09/to-build-theworkforce-of-the-future-we-need-to-revolutionize-how-we-learnwecome-to-digital-learning-2-0

Kelly, G., \& Tomlinson, D. (2016). The future of trade unionism and the next generation. In N. Tyrone (Ed.), What is the future of trade unionism in Britain. Northants, UK: Corby.

Keune, M. (2015). Shaping the future of industrial relations in the EU: Ideas, paradoxes and drivers of change. International Labour Review, 154(1), 47-56. doi:10.1111/j.1564-913x.2015.00225.x

Kirby, P. (2016). What do we need trade unions for? In N. Tyrone (Ed.), What is the future of trade unionism in Britain. Northants, UK: Corby.

Nowak, P. (2015). The past and future of trade unionism. Employee Relations, 37(6), 683 - 691. doi:10.1108/er-04-2015-0064

Standing, G. (2011). The precariat: The new dangerous class. London, UK: Bloomsbury.

Standing, G. (2018). The precariat: Today's transformative class? Great Transition Initiative. $\quad$ Retrieved from https://greattransition.org/publication/precariat-transformativeclass

Tait, C. (2017). Future unions. Towards a membership renaissance in the private sector. London, UK: Fabian Society. Retrieved from 
https://www.fabians.org.uk/wp-content/uploads/2017/11/FabianSociety Future-Unions-report.pdf

Taleb, N. N. (2018). Skin in the game: Hidden asymmetries in daily life. New York, USA: Random House.

Taylor, R. (2001). The future of employment relations. Swindon, UK: Economic and Social Research Council, Polaris Hous.

Tegmark, M. (2017). Life 3.0: Being buman in the age of artificial intelligence. New York, USA: Alfred A. Knopf.

Rotilă, V. (2018). The predictions on the future of labour are not grounded; Some arguments for a bayesian approach. Postmodern Openings, 9(3), 36-63. doi: $10.18662 / \mathrm{po} / 35$

Schnabel, C., \& Wagner, J. (1994). Industrial relations and trade union effects on innovation in Germany. Labour, 8(3), 489-504. doi:10.1111/j.14679914.1994.tb00173.x

Yudkowsky, E. (2004). Coherent extrapolated volition. San Francisco, USA: The Singularity Institute. Retrieved from https://intelligence.org/files/CEV.pdf

Zweig, D. (2015). Invisibles: The power of anonymous work in an age of relentless selfPromotion. New York, USA: Penguin Random House. 